\title{
Prácticas de lectura y escritura medieval en la compilación de las historias piadosas del Ms. Esc. h-I-13
}

Carina Zubillaga Universidad de Buenos Aires

El manuscrito h-I-13 de la Biblioteca de San Lorenzo de El Escorial, datado entre mediados del siglo XIV y principios del siglo XV, está integrado por nueve historias piadosas que avanzan en el espacio codicológico desde las tres primeras vidas de santas (De Santa María Madalena, Aquí comiença la vida de Santa Marta, Aquí comiença la estoria de Santa María Egiçiaca) hacia las siguientes dos passiones de Catalina de Alejandría y Eustaquio (Del enperador Costantino, De un cavallero Pláçidas que fue después christiano e ovo nonbre Eustaçio) y los últimos cuatro romances (Aqui comiença la estoria del rey Guillelme, Aquí comiença el cuento muy fermoso del enperador Otas de Roma e de la infante Florençia su fija e del buen cavallero Esmero, Aqui comiença un muy fermoso cuento de una santa enperatrís que ovo en Roma e de su castidat, Aquí comiença un noble cuento del enperador Carlos Maynes de Roma e de la buena enperatrís Sevilla su mugier), en una yuxtaposición genérica que no borra los límites entre los géneros sino que los integra a partir de la unidad codicológica, paleográfica, lingüística y fundamentalmente temática de los relatos en su contexto manuscrito.

Las historias del Ms. Esc. h-I-13 merecieron un grado similar de atención particular en el pasado, lo que dio lugar a algunas pocas ediciones singulares de cada uno de los textos que los mantuvo en un segundo aunque siempre aludido plano frente a las consideradas grandes obras hispánicas medievales; recién en el año 1982 el trabajo pionero de John R. Maier y Thomas D. Spaccarelli consideró todas las historias en conjunto como parte de un manuscrito individual que al reunirlas 
indefectiblemente las relacionaba entre sí $^{1}$. A este trabajo continuaron las aproximaciones a la unidad del códice y la disposición ordenada y previamente pautada de los relatos de Francisco Rico, el propio Spaccarelli, Fernando Gómez Redondo, Emily C. Francomano, John K. Moore, Jr. y Spaccarelli, de nuevo Moore, Jr., y yo misma ${ }^{2}$.

La denominación del códice en su conjunto como "libro de los huéspedes", acuñada en principio por Spaccarelli ${ }^{3}$ y desarrollada luego con más profundidad por Moore, Jr. y Spaccarellii ${ }^{4}$, enfocando la relación del texto y las imágenes presentes en el manuscrito, y por Moore, Jr. más tarde en su edición del códice ${ }^{5}$, tiene en cuenta particularmente al posible receptor del Ms. Esc. h-I-13: peregrinos, en especial mujeres, que en el trayecto del Camino de Santiago habrían encontrado en el códice ejemplos piadosos de otros hombres y mujeres también en vías de consolidar su fe cristiana ${ }^{6}$. El presente trabajo se orienta en cambio no

${ }^{1}$ John R. Maier and Thomas D. Spaccarelli, "MS. Escurialense h-I-13: Approaches to a Medieval Anthology”, La Corónica, 11 (1982), pp. 18-34.

${ }^{2}$ Francisco Rico, "Entre el códice y el libro (Notas sobre los paradigmas misceláneos y la literatura del siglo XIV)", Romance Philology, LI.2 (1997), pp. 151-169; Thomas D. Spaccarelli, Pilgrim's Companion: Reassessing "El libro de los huéspedes" (Escorial MS. H.I.13), University of North Carolina, Chapel Hill, 1998; Fernando Gómez Redondo, Historia de la prosa medieval castellana. II: El desarrollo de los géneros. La ficción caballeresca y el orden religioso, Cátedra, Madrid, 1999; Emily C. Francomano, “'Lady, you are quite a chatterbox': The Legend of St. Katherine of Alexandria, Wives' Words, and Women's Wisdom in MS Escorial h-I-13", St. Katherine of Alexandria: Texts and Contexts in Western Medieval Europe, Jacqueline Jenkins and Katherine J. Lewis, eds., Brepols, Turnhout, 2003, pp. 131-152; John K. Moore, Jr. and Thomas Spaccarelli, "Libro de los huéspedes (Escorial MS h.I.13): A Unified Work of Narrative and Image for Female Pilgrims", La Corónica, 35 (2006), pp. 249-270. Las dos únicas ediciones críticas del códice en su conjunto son del mismo año: John K. Moore, Jr., ed., Libro de los huéspedes (Escorial MS h.I.13): A Critical Edition, ACMRS, Arizona, 2008; Carina Zubillaga, ed., Antología castellana de relatos medievales (Ms. Esc. h-I-13), SECRIT, Buenos Aires, 2008.

${ }^{3}$ Thomas D. Spaccarelli, op. cit.

${ }^{4}$ John K. Moore, Jr. and Thomas Spaccarelli, "Libro de los huéspedes”, en op. cit.

${ }^{5}$ John K. Moore, Jr., op. cit.

${ }^{6}$ La posible recepción femenina del códice en su conjunto también está planteada por Emily C. Francomano, "Lady, you are quite a chatterbox", en op. cit., pp. 131, 134, 136-137; Fernando Gómez Redondo, op. cit., pp. 1936-1937; y Cristina González, "Vna santa enperatris: novela esquizofrénica", Homenatge a Josep Roca-Pons: Estudis de llengua i literatura, Jane White Albrecht, Janet Ann De Cesaris, Patricia V. Junn and Josep Miquel Sobrer, eds., Publicacions de l'Abadia de Montserrat, Barcelona, 1991, pp. 153-165 (p. 165). 
a la figura del receptor ni tampoco a la del autor, multiplicada en cada una de las historias singulares que integran el manuscrito, sino al compilador del códice, pues en la dinámica de su tarea está el cruce de la lectura y de la escritura medieval como prácticas cohesionadas y cohesivas que resultan determinantes en la consideración del manuscrito como una unidad en sus facetas tanto receptivas como creativas. Esas prácticas aparecen representadas en los relatos que componen el códice, y a partir de su rastreo y el análisis de su finalidad y significación se intentarán deslindar tanto los explícitos como los sobreentendidos acerca de la dinámica de la compilación manuscrita en la Edad Media.

La idea básica y orientación de este trabajo, centrado en el ejercicio compilatorio como eje que da cuenta tanto de la lectura como de la escritura medieval en tanto prácticas íntimamente relacionadas, se apoya en la consideración del códice h-I-13 como una antología, según el término planteado por Maier y Spaccarelli y luego asumido en la edición conjunta del códice por mí misma ${ }^{7}$. En su trabajo de 1982, estos estudiosos distinguen al códice como "a highly organized anthology of tales which were collected and ordered (and probably translated) with several specific criteria in mind"s. Frente al fragmentarismo de las ediciones y acercamientos previos, Maier y Spaccarelli sentaron las bases para una perspectiva más global de la transmisión y recepción manuscritas.

Acerca de la caracterización de un manuscrito medieval como antológico, Theo Stemmler remite directamente a la figura de un compilador que aplica una serie de parámetros para establecer un orden de los textos en su copia manuscrita $^{9}$. Esos principios de organización están ligados a la idea de asociaciones que generan lazos y que suponen una serie de actividades complementarias: leer, traducir, ordenar, disponer, componer, entre otras, que se evidencian de manera tanto física como textual en la unidad manuscrita.

\footnotetext{
${ }^{7}$ Carina Zubillaga, op. cit.

${ }^{8}$ John R. Maier and Thomas D. Spaccarelli, “MS. Escurialense h-I-13”, en op. cit., p. 20.

${ }^{9}$ Theo Stemmler, "Miscellany or Anthology? The Structure of Medieval Manuscripts: MS: Harley 2253, for Example", Zeitschrift für Anglistik und Amerikanistik, 39 (1991), pp. 231-237.
} 
Como declaro en la descripción del Ms. Esc. h-I-13 previa a mi edición, "La composición física del volumen es el aspecto más visible de su unidad" ${ }^{\text {. A la }}$ uniformidad de copia dada por el uso consistente del formato de escritura a doble columna y el programa de rúbricas y decoración manuscrita, rudimentario pero significativo, también se suman la unidad lingüística del códice, pues todos los relatos son traducciones castellanas de textos franceses en prosa de transmisión independiente ${ }^{11}$, y la unidad temática como principio general de la disposición de las historias en el manuscrito. A pesar de que los primeros cinco relatos pertenecen al género hagiográfico y los últimos cuatro pueden calificarse como historias de aventuras, el tema de la prueba cristiana y del desarrollo de la paciencia y de la virtud a partir de múltiples peligros y padecimientos como obstáculo narrativo y de la aventura a superar como estructura textual se reitera en cada una de las historias. Es el camino de santidad que cada uno de los protagonistas de las narraciones elige, incluso con la adversidad que conlleva y que es necesaria como medio de purificación espiritual, el que unifica todas las historias a pesar de su evidente diversidad; santos, mártires, reyes y reinas representan modelos posibles y variados de conducta cristiana en tiempos y lugares disímiles, pero con la referencia última a Cristo como paradigma indiscutido.

La compilatio es definida por M. B. Parkes "both as a form of writing and as a means of making material easily accessible"12. Como procedimiento configurador de sentido, entonces, la compilación manuscrita medieval reescribe las historias recibidas a partir de tradiciones específicas y amplía su significado para

\footnotetext{
${ }^{10}$ Carina Zubillaga, op. cit., p. XV. Remito a esa descripción para ahondar en las características materiales de la conformación del volumen, fundamentales para la valoración del códice como un artefacto histórico y no un mero repositorio textual. Como plantea al respecto Stephen G. Nichols, "Introduction", The Whole Book. Cultural Perspectives on the Medieval Miscellany, Stephen G. Nichols and Siegfried Wenzel, eds., The University of Michigan Press, Ann Arbor, 1996, pp. 1-6, los manuscritos nunca son vehículos transparentes o neutrales, sino que poseen una identidad tipológica en la que es preciso profundizar para avanzar más allá de la crítica textual hacia la consideración del contexto manuscrito de los textos estudiados.

${ }^{11}$ A pesar de que la lengua general es el castellano, se destacan en todas las historias rasgos occidentales atribuibles al copista. Para el estudio más reciente de los relatos del Ms. Esc. h-I-13 como traducciones remito a Marco Maulu, Tradurre nel medioevo: il ms. escorialense h-I-13, Pàtron, Bologna, 2009.

${ }^{12}$ M. B. Parkes, "The Influence of the Concepts of Ordinatio and Compilatio on the Development of the Book", Medieval Learning and Literature: Essays Presented to Richard William Hunt, J. J. G. Alexander and M. T. Gibson, eds., Clarendon Press, Oxford, 1976, pp. 115-141 (p. 127).
} 
el receptor, a través de la dispositio como elemento dinámico que en la instantaneidad del códice como soporte reduce la distancia entre la escritura y la lectura; es la disposición del manuscrito como un conjunto textual uniforme, en definitiva, lo que hace emerger el carácter colectivo de cada texto en su contexto manuscrito, redefiniendo su singularidad a través de la estabilidad que adquiere en la unidad del espacio codicológico.

La consideración crítica de la compilación como trabajo editorial puede relacionarse con el análisis acerca del escriba como editor de Elspeth Kennedy sobre la tradición prosística medieval francesa, quien postula posibles modernizaciones de palabras y/o construcciones arcaicas, aclaraciones de inconsistencias, adiciones o supresiones tendientes a explicitar el sentido de los textos ${ }^{13}$, además de con los estudios de Timothy A. Shonk sobre el conocido manuscrito Auchinleck ${ }^{14}$ y de Sylvia Huot también sobre la prosa francesa ${ }^{15}$. La tarea del compilador puede equipararse en este sentido a la labor del editor; no a la del autor, debido a que no hay en general reformulación de los textos, ni solo a la del lector, ya que su lectura está en función de disponer un texto o textos apropiados para quienes serán sus siguientes lectores, en función de sus propios criterios o los de un patrono o responsable que le encomienda el trabajo. En la figura del compilador se da de manera privilegiada el cruce entre la lectura y la escritura medieval; su papel es el de mediador entre las intenciones autorales, la lectura activa de los textos y la reescritura a través de esa experiencia de lectura entendida en su continuidad.

La transmisión de la literatura medieval no es un proceso pasivo; todo lo contrario, da cuenta de la producción del periodo como un proceso colaborativo entre el autor y sus continuadores. Esta idea de continuidad se percibe particularmente en un códice antológico como el h-I-13 en el cual la reunión previa, disposición y ordenamiento de las historias en el marco del manuscrito unitario suponen un continuum en el que cada relato se concibe como parte integrante de un conjunto

\footnotetext{
${ }^{13}$ Elspeth Kennedy, "The scribe as editor", Mélanges de langue et de Littérature du Moyen Age et de la Renaissance Offerts à Jean Frappier, Libraire Droz, Genève, 1970, tomo I, pp. 523-531.

${ }^{14}$ Timothy A. Shonk, "The Scribe as Editor: The primary Scribe of the Auchinleck", Manuscripta, 27 (1983), pp. 19-20.

${ }^{15}$ Sylvia Huot, "The Scribe as Editor: Rubrication as Critical Apparatus in Two Manuscripts of the Roman de la Rose”, L'Espirit Créatur, XXVII.1 (1987), pp. 67-78.
} 
mayor, de una historia inacabable que se reitera una y otra vez a través de las referencias a la escritura y la lectura omnipresentes en cada relato.

Ni la escritura ni la lectura se conciben en términos individuales en el Ms. Esc. h-I-13; no hay escritura individual ni fijación individual de la escritura, y asimismo la lectura a la vez se refiere y se postula como programa colectivo, lo que queda claro en las sucesivas menciones que pueden rastrearse en el códice.

En Santa Marta, la segunda de las leyendas hagiográficas que integra el códice h-I-13, la función tanto de la escritura como de la lectura resulta fundamental no solo para el significado concreto de la historia de la santa asociada a la vida activa sino para su sentido conjunto como práctica ligada a la actividad compilatoria y, por ende, al manuscrito como unidad. El concepto mismo de la vida como un escrito se explicita en la oración que la santa dirige a Dios en el momento de su muerte y sintetiza el temor frente al pecado, que asume la forma del mal que se consigna por escrito y que puede leerse como prueba de un posible castigo: "Buen Padre, buen Huésped; estos diablos son aquí por me llevar, e tienen en escrito los males que yo fize, e dizen: 'Vayámosla tomar, ca Dios la desanparó, e non ha quien nos la defienda" " $(28)^{16}$. La equiparación de la vida humana con su registro escrito termina de definirse con el misterio de la Encarnación como síntesis vital, cuya lectura funciona como el conjuro contra la tentación diabólica previa y como preparación para la propia muerte de la santa: "Entonçe mandó que le leyesen la pasión de Jhesu Christo que ella troxiera de Jherusalem escripta en ebraico. E después que fue llevada, dixo: 'Buen Padre, en tus manos encomiendo el mi spíritu'. Entonçe espiró, e sant Migel tomó el alma en sus manos e llevola a los çielos, e apresentola ante Jhesu Christo" (30).

La identificación de la vida de todo hombre con la escritura como imagen privilegiada se revela como una metáfora cristiana del lazo inquebrantable entre Cristo y sus seguidores cuando el mismo Jesús le muestra a un fraile que acompaña al obispo San Frontes, en su traslado sobrenatural al entierro de Santa Marta, un libro que es figura de la redención cristiana: "E en todo aquel libro non avía escripto más de un bielso que dizía: 'En mía remenbrança perdurable será mi huéspeda, e non duldará ningunt mal al postremero día'. Desý cató todas las fojas

\footnotetext{
${ }^{16}$ Las citas corresponden a mi edición conjunta del Ms. Esc. h-I-13 (Carina Zubillaga, op. cit.), indicándose a continuación de cada una el número de página correspondiente.
} 
del libro e non falló ý ál sinón este vielso escripto en cada foja" (32-33). Este libro santo que simboliza el triunfo de la vida sobre la muerte en la entrega de Cristo identifica el sentido unitario de cada existencia terrena como reflejo de esa alianza establecida de una vez y para siempre; por eso, el verso que se repite en cada página es en todos los casos el mismo y enlaza a Jesús con Santa Marta como representante de todo cristiano. Además de hacer presente la alianza divina entre Cristo y la humanidad por la que se entregó, ese libro también remite indudablemente al códice en su conjunto como la suma de historias cuyo sentido último, a pesar de ser distintas y referir a protagonistas particulares, puede identificarse con la virtud cristiana como eje tanto vital, que reafirma el triunfo de la vida perdurable sobre la perecedera, como textual, ya que compendia la funcionalidad de la lectura de todas las historias piadosas presentes en el Ms. Esc. h-I-13.

En el final de la historia de Santa Marta, el narrador resume el destino de quienes acompañaron a la servidora de Cristo en su predicación, destacando por última vez y de manera conclusiva la idea de la escritura de la propia vida - en este caso la de Sintex - como testimonio siempre nuevo aunque reiterado de la existencia humana como camino virtuoso hacia la vida verdadera, otra más entre las buenas obras que son reflejo de la imitatio Christi:

Marçilla e Syntex e Epafras, leales e buenos, se fueron d'allý a Esclavonia. E pedricaron allý el nonbre de Dios, e bivieron en buenas obras. E Marçilla vivió después de santa Marta diez años. E Sintex escrivió su vida en un quaderno pequeño. Mas Encodes e Parmenas e Germán e Sostenes, que santa Marta criaran, servieron en aquella eglesia do la sepultura de santa Marta era mientre bivieron; e allý finaron. (34-35)

A pesar de que estas referencias a la vida como escritura que puede leerse como testimonio de la fe cristiana aparecen en reiteradas oportunidades en Santa Marta y en cambio no se mencionan en Santa María Madalena, la historia que abre el códice h-I-13, la misma dinámica compilatoria permite incluir la una en la otra, como las dos caras de una misma moneda identificable en la figura de las hermanas y posiblemente representada por la inicial iluminada que da comienzo tanto al primer relato como al manuscrito en su conjunto, donde dos rostros femeninos enfrentados parecen preanunciar la unión indisoluble de la vida de las hermanas 
María Magdalena y Marta a pesar de la individualización de sus historias como vías de perfeccionamiento cristiano ${ }^{17}$.

El relato de la vida de Santa Marta comienza unificando en la figura de las dos hermanas el destino de la Iglesia y distinguiendo recién sus caminos individuales posteriores a partir de la diferenciación establecida por Jesús en Betania acerca de la vida contemplativa y de la vida activa como modalidades de vida cristiana:

E allí estableçió Él toda religión, e abrió los sacramentos de santa eglesia. E en aquella casa fizo Él una eglesia de dos maneras de vida, que llaman en latín contenplativa e activa. Contenplativa vida es de los çielos, e activa vida es del mundo; e diolas a estas ermanas anbas, la contenplativa a santa María Madalena e la activa a santa Marta; e otrosí las dio a todos aquellos que después vernán que bevir querrán segunt el estado de santa eglesia. En estas dos vidas son todas las reglas de religión e de orden, e los enseñamientos del Viejo Testamento e del Nuevo por que los santos e los amigos de Dios son idos e irán a los çielos. Sy nós amáremos nuestro próximo así como a nós mesmos, e ayudarmos segunt nuestro poder, averemos la vida activa con santa Marta. E sy nós amáremos a Dios más que a todas las otras cosas, e despreçiáremos las cosas terrenales, averemos la vida contenplativa con santa María Madalena. (18)

La historia que abre el códice h-I-13 retoma la parte final de la leyenda de María Magdalena, subrayando la vida ascética de la pecadora arrepentida que viaja a Marsella junto a sus hermanos Marta y Lázaro para predicar la palabra de Dios. El prototipo occidental de la figura de la santa, cuya identidad se unifica a partir de tres mujeres distintas presentes en los Evangelios (María de Betania tal como aparece en Juan 11, 2, una pecadora que se arroja a los pies de Jesús en la casa de Simón el Fariseo en Lucas 7, 37, y finalmente aquella a quien Cristo libera de siete demonios en Lucas 8, 2), conforma el modelo de la prostituta redimida como

\footnotetext{
${ }^{17}$ John K. Moore, Jr. and Thomas Spaccarelli, "Libro de los huéspedes”, en op. cit., pp. 253-255, analizan en detalle esta inicial considerando la probable representación de Santa María Magdalena y Santa Marta, aunque extendiendo su alcance como motivo visual femenino reiterado en el códice.
} 
figura clave para remarcar la importancia del arrepentimiento en el Cristianismo medieval ${ }^{18}$.

Santa María Egiçiaca vuelve a relacionarse con los relatos precedentes en el Ms. Esc. h-I-13 a partir de este mito hagiográfico de la prostituta santa, al que pertenecen tanto María Egipciaca como María Magdalena, y de la escritura y la lectura como imágenes determinantes del sentido de la vida cristiana, de nuevo asociadas directamente al milagro como expresión de la unión inquebrantable entre lo humano y lo divino.

La figura de la pecadora arrepentida se estructura en la leyenda de María Egipciaca a través del contraste entre su vida lujuriosa de juventud y su ascetismo extremo después de la conversión, que la lleva a permanecer más de cuarenta años en el desierto hasta el momento mismo de su muerte ${ }^{19}$. La devoción a las penitentes se incrementa a partir del siglo XII — momento de conformación de la tradición occidental de la leyenda de María Egipciaca - de manera paralela al auge mariano, a través de una afectividad laica que encuentra en las imágenes de lo femenino una medida posible de su propio progreso espiritual, en particular

\footnotetext{
${ }^{18}$ Para profundizar en la construcción de la figura de María Magdalena como penitente remito especialmente a Victor Saxer, Le Culte de Marie Madeleine en Occident, des origines à la fin du Moyen Âge, Clavreuil, Paris, 1959; J. K. Walsh and B. Bussell Thompson, The Myth of the Magdalen in Early Spanish Literature (with an Edition of the "Vida de Santa Maria Madalena" in Ms. h.I.13 of the Escorial Library), Lorenzo Clemente, New York, 1986; y Ana María Rodado Ruiz, "La santa María de Mágdalo en la literatura castellana de la cuaderna vía clerical", Actas II Congreso Internacional de la Asociación Hispánica de Literatura Medieval (Segovia, del 5 al 19 de octubre de 1987), Universidad de Alcalá, Alcalá de Henares, 1992, tomo II, pp. 709-721.

${ }^{19}$ La combinación de sexualidad y eremitismo extravagantes es en gran medida el motivo de la popularidad que adquiere la leyenda en su versión occidental centrada en el protagonismo femenino, frente a la oriental focalizada en cambio en el monje que encuentra a María en el desierto y enmienda su vida a partir del ejemplo de la asceta. Para ahondar en la evolución de la leyenda de María de Egipto remito a Roger Walker, ed., Estoria de Santa María Egiçiaca, University of Exeter, Exeter, 1972; Duncan Robertson, "Poem and Spirit. The Twelfth-Century French 'Life' of Saint Mary the Egyptian", Medioevo Romanzo, VII.3 (1980), pp. 305-327; Joseph T. Snow, "Notes on the Fourteenth-Century Spanish Translation of Paul the Deacon's Vita Sanctae Mariae Aegyptiacae, Meretricis", Saints and their Authors: Studies in Medieval Hispanic Hagiography in Honor of John K. Walsh, Jane E. Connolly, Alan Deyermond, Brian Dutton, eds., Hispanic Seminary of Medieval Studies, Madison, 1990, pp. 83-96; y E. Ernesto Delgado, “Ascetas y penitentes en el discurso de los Padres de la Iglesia: hacia una revisión histórica del modelo hagiográfico de la leyenda de Santa María Egipcíaca en la Alta Edad Media”, Romance Quarterly, 50.4 (2003), pp. 281-301.
} 
mediante la identificación con mujeres que han alcanzado la salvación luego de una vida dedicada previamente al pecado; si ellas fueron perdonadas cualquiera puede serlo, parece ser el imperativo que propició la actualización y desarrollo creciente de estas historias. Como plantea Dayle Seidenspinner-Núñez, "In dramatizing acts of conversion, repentance, confession, and penance, the harlot-saint legends - more immediately and directly than teaching or sermonizing - communicated doctrine to the reader or listener as concrete experiences to be shared rather than as abstract concepts or theories" ${ }^{20}$.

Es nuevamente el momento de la muerte del santo, como en el caso anterior de Santa Marta, el que desencadena las asociaciones de la escritura y de la lectura con el sentido de la vida cristiana y, de manera extensiva, su transmisión testimonial. Cuando el monje Zózimas descubre el cuerpo ya sin vida de María Egipciaca en el desierto, como esta le había anunciado previamente que lo haría, también encuentra unas letras escritas en tierra de procedencia evidentemente sobrenatural: "'Padre Zózimas, mete so tierra el cativo cuerpo de María. Da a la tierra lo que es suyo, e ruega por mí'. Esto fue nueve días andados de abril ante de Pascua. E quando el buen omne vio las letras e las leyó, maravillose mucho quién las escriviera ý, que ella le dexiera que nunca liera" (54).

El milagro del entierro del cuerpo de la santa, que se desdobla en las indicaciones sobrehumanas de cómo concretarlo y en el león que aparece para ayudar a Zózimas en la tarea, concentra en la escritura y lectura santas — sin aprendizaje previo - y en la figura del león reverente capaz de cavar la tierra para enterrar allí a María el quiebre de toda ley natural propio del milagro como manifestación de lo divino en lo terreno. Particularmente es la escritura, sin embargo, la señal primera y a la vez definitiva de la santidad alcanzada por la otrora pecadora, expresada como milagro y reafirmada de ese modo como lazo entre la existencia humana y la vida eterna, debido a la gracia salvífica cristiana prometida y concretada incluso en la más grande de las pecadoras a causa de su arrepentimiento, conversión y penitencia como eje transformador de su vida que se testimonia en su muerte santa.

El martirio de Santa Catalina de Alejandría, cuarta historia del códice h-I-13, se concentra en el prototipo de la doncella sabia resignificado según la medida de

\footnotetext{
${ }^{20}$ Dayle Seidenspinner-Núñez, "The Poetics of (Non) Conversion: The Vida de Santa María Egipçiaca and La Celestina", Medievalia et Humanistica, 18 (1992), pp. 95-128 (p. 100).
} 
la sabiduría cristiana, ya que aunque desde el principio se destaca a la joven como letrada ("Esta donzella pusiera su padre a ler de que fuera pequeña por aprender las artes", 58) las primeras palabras con las que se enfrenta al emperador dan cuenta de la subordinación de sus múltiples saberes a su fe en Cristo ("Los dios non son muchos, mas un Dios, formador de aquéllos, que naçió e que vivió e que fizo e crió todas las cosas del mundo e partió e devisó por su mandamiento", 59). Es sin embargo en la disputa de la virgen con los cincuenta maestros escogidos por el emperador para denostar su fe cuando y donde de modo más específico el saber libresco se reformula como razonamiento vano frente a las palabras de verdad de las Sagradas Escrituras:

Mas yo non quiero que me tengades por vençida, ca yo vos quiero dar por testimonio los vuestros spíritus lixosos que vós orades, que son diablos; otrosý vos quiero dar los vuestros outores por testimonio por provar la fe de Jhesu Christo, ca yo puedo asaz fallar mejores testimonios buenos e linpios de santa Escriptura que es fecha por Santo Spíritu. E muy fermosa cosa me semeja e grant vitoria e onrada de vençer omne sus enemigos por sus armas mesmas e liarlos con sus lazos e confonderlos por testimonio de sus outores, ca vós non reçelaredes los testimonios de los que creedes. (66)

El debate central que enfrenta a Catalina con los filósofos, acerca de la doble naturaleza humana y divina de Cristo, es la clave del misterio de la Encarnación y de la gracia salvífica que triunfa sobre todos los razonamientos de las autoridades letradas y acaba con la conversión y sucesivo martirio de los eruditos que son bautizados por su propia sangre al morir en el fuego al que son enviados como castigo por el emperador ${ }^{21}$.

La imagen desarrollada en el Ms. Esc. h-I-13 del registro de toda vida humana como escritura celestial se reafirma con los sucesivos allegados al emperador a quienes la palabra de la santa convierte: su propia esposa y su principal caballero, el jefe del ejército Porfirio, de quien Catalina afirma lo siguiente a unos ángeles

${ }^{21}$ El debate como dispositivo narrativo y configurador principal de la passio de Santa Catalina de Alejandría y la defensa verbal de su castidad es analizado por Emily C. Francomano, "Lady, you are quite a chatterbox", en op. cit., pp. 131-152. 
que la amparan mientras es retenida como prisionera: "E queremos asý que aquel cavallero que con ella es, que sea escripto en el nonbre e en la parte de nuestra cavallería" (71). Ambos son también martirizados, al igual que los cincuenta sabios a los que la santa vence en sus argumentos, lo que sin dudas preanuncia su propia muerte como mártir ${ }^{22}$.

El también mártir Eustaquio, protagonista de la quinta historia del códice h-I13, es asimismo un venerable caballero romano que como Porfirio en el relato anterior se convierte a causa de la revelación cristiana y abandona su vida anterior - e incluso también su nombre, Plácidas - para volverse un servidor de Cristo y testimoniar con su propia vida el camino existencial de todo cristiano, aquí bajo el conocido tema del hombre probado por el destino, demostrando su virtud luego de innumerables pérdidas y sufrimientos ${ }^{23}$.

Ya al principio del relato Plácidas se manifiesta como un caballero que parece cristiano sin serlo, debido tanto a su buena conducta como a su comportamiento ejemplar: "A todos dava él consejo a todo su poder: vestía los desnudos, dava a comer a los que avían fanbre, mantenía las biudas e los huérfanos, pagava las debdas por los cuitados debdores; a cavalleros e a dueñas pobres acorría bien a sus coitas" (81). Es esto lo que promueve que Jesús mismo aparezca ante él en los cuernos de un ciervo que sale a cazar y se efectivice así su conversión, avalada en las Sagradas Escrituras como afirmación de lo verdadero:

Mas nuestro Señor, el poderoso e de buen talante, que sabe e ve quáles ha de llamar e de tirar a sý, non tovo en desdén las buenas obras de aquel alto omne; pero era cobierto de nuve de yerro e de descrençia, non quiso dexar sus buenos fechos sin gualardón. Ca, asý como dize la santa Escriptura, todas las maneras de las gentes que Dios temen e aman, e que entienden derecho e razón, plazen a nuestro Señor. Por esto ovo Él piadat

\footnotetext{
${ }^{22}$ La gradación ascendente de los martirios en la narración es señalada por Bruce A. Beatie, "Saint Katharine of Alexandria: Traditional Themes and the Development of a Medieval German Hagiographic Narrative", Speculum, LII. 4 (1977), pp. 785-800, quien destaca la técnica de la repetición - de las pruebas afrontadas por Catalina, de las conversiones y de las muertes que le siguen - como causante del incremento que culmina con el momento climático del martirio de la santa.

${ }^{23}$ El modelo bíblico de la prueba del protagonista y de su familia es Job, arquetipo de la paciencia frente al sufrimiento que conforma la base del motivo.
} 
d'aquel alto omne, e quísolo salvar en qual guisa vos agora diremos. (81-82)

No hay alusiones significativas a la escritura ni a la lectura en Guillelme, el próximo relato del Ms. Esc. h-I-13 que inaugura las historias de aventuras pertenecientes ya al género del romance y no al hagiográfico previo; sin embargo, su relación con la historia anterior de Plácidas es clara a partir del tema compartido por ambas, el del hombre probado por el destino. Esta versión secularizada de la vida del cristiano como peregrinatio posee una circularidad mayor que la que implicaba para Eustaquio y su familia la muerte como mártires, ya que todo aquello que Guillermo, su esposa y sus hijos pierden como prueba de su virtud cristiana es recuperado al final de la historia y sumado al aprendizaje de la humildad y la paciencia para soportar el sufrimiento que convertirán al rey inglés en un mejor gobernante para su pueblo, a partir de la incorporación del paradigma ético cristiano como modelo de vida desarrollado en cada acción cotidiana, ya sea que esta tenga alcances solo individuales, familiares o políticos más amplios ${ }^{24}$.

El inicio de Otas de Roma muestra a Florencia, la verdadera protagonista de la séptima historia que integra el códice h-I-13, como una doncella sabia del todo similar a Santa Catalina de Alejandría, tanto en belleza y bondad como en esmerada educación: "Mas esta Florençia de que vos fablo, de muy grant bondat, quando llegó a hedat de quinze años fue tan bella e tan cortés e tan bien enseñada que en todo el mundo non le sabían par" (140). Es sin embargo su conocimiento letrado el que se destaca por encima de todas sus cualidades ("Ya de las escripturas nin de las estorias ninguno non sabía más", 140), aquí claramente como un don divino y un componente fundamental de su virtud, que se manifiesta en especial como un encanto que resulta irresistible para los demás ("con todo esto le diera Dios tal donaire que non se abondavan las gentes de oír su palabra, onde ella era mucho abondada e mucho conplida", 140).

\footnotetext{
${ }^{24}$ Más allá de las diferencias entre sus protagonistas, ya que Plácidas es un caballero romano que se convierte en santo y Guillermo un rey inglés que ejercita de manera secular la virtud cristiana como forma de vida y sustento de su ética política como gobernante, las similitudes entre las historias que comparten el tema de la prueba cristiana son destacadas particularmente por John R. Maier, ed., El rrey Guillelme, University of Exeter, Exeter, 1984; y por Shirley Liffen, "The transformation of a passio into a romance: A study of two fourteenth-century Spanish versions of the legends of St Eustace and King William of England", Iberoromania, 41 (1995), pp. 1-16.
} 
Las referencias a las Sagradas Escrituras son constantes en el relato de la vida de Florencia de Roma, a pesar de la secularización de las virtudes femeninas propia del motivo que engloba las últimas tres narraciones del manuscrito: el de la princesa o reina injustamente acusada de adulterio que se mantiene firme frente a las reiteradas y numerosas tribulaciones que debe padecer $^{25}$. De manera significativa, la palabra sacra está asociada en el texto a la historia que se cuenta, en idéntico nivel y cotejándose las historias sagradas y la de la propia Florencia como parte de un mismo devenir asumido históricamente:

E asý como fallamos escripto, desde que Dios veno en tierra prender carne de la Virgen santa María por la salut del ángel, nunca por una mugier fue tan grant destruimient como fue por Florençia, la fija del rey Otas. Señores, aquesta estoria non es de oy nin de ayer; ante es de tienpo antiguo. El enperador Garsir era muy preçiado e era muy buen guerrero, segunt cuenta la escriptura, de guisa que a su tienpo non fue ninguno tan fuerte nin tan fiero, asý que se non tomó con tal que lo non metiese so su poder. Él era destruidor de sus enemigos e ensalçador de sus amigos. (169-170)

La escritura iguala las historias sagradas y las profanas, lo que se comprueba también en las referencias milagrosas de numerosos episodios de Otas de Roma, como por ejemplo en la descripción de la habitación sobrenatural en la que alojan a Florencia sufriente de dolor por la muerte de su padre: "E cuenta la escriptura que la llevaron dende esmoreçida, e fuéronla echar en una su cámara muy rica en que avía muy ricas piedras preçiosas que davan muy grant claridat" (186). Las cualidades curativas de la habitación, capaz de quitar todo pesar, son directamente relacionadas con el poder de Dios tanto sobre la doncella como sobre la muerte y el dolor que esta supone.

En el momento de mayor prueba de Florencia, el que la define como heroína injustamente acusada de asesinar a una niña a su cargo y vuelve a ligarla tanto con las otras dos protagonistas posteriores de historias de acusaciones injustas

\footnotetext{
${ }^{25} \mathrm{El}$ arquetipo de estas heroínas de múltiples nombres y procedencias - Crescentia, Contanza, entre muchas otras - es abordado en su denominación concreta y caracterización por Margaret Schlauch, Chaucer's Constance and Accused Queens, New York University Press, New York, 1927.
} 
como con las santas y mártires de las hagiografías iniciales del Ms. Esc. h-I-13, la mujer dirige una oración a Dios pidiéndole su ayuda y la referencia a las Sagradas Escrituras determina con claridad el sentido de su prueba como prueba cristiana y la medida de su fe: "Nuestro Señor Jhesu Christo, quien en vós cree firmemente, como diz la Escriptura, non puede ser perdido" $(239)^{26}$.

Una santa enperatrís, el relato que sigue a Otas de Roma en el códice h-I-13, también contiene desde su mismo inicio numerosas remisiones a las Sagradas Escrituras que permiten incluir la historia que se contará en un corpus más amplio ligado al desarrollo de la vida cristiana en el Imperio romano: "La Escriptura diz asý que el grant Prínçipe de gloria que bive e regna sobre todos prínçipes, que escogió el grant enperio de Roma para sý, e quiso que la su fe fuese en Roma ensalçada e mantenida" (275). Pero no sólo la delimitación geográfico-temporal del relato que se contará se establece a través de lazos escriturarios, sino también las temáticas que resultarán centrales para el desarrollo de la historia; así sucede por ejemplo con la relación matrimonial, cuya naturaleza espiritual se pauta en asociación con la palabra santa, en especial acerca de cómo debe el hombre comportarse con su mujer: "E otrosí diz la Escriptura que la deve amar como Jhesu Christo la santa eglesia, por que sofrió muerte en cruz, e como a Dios mesmamente; ésta es la çima" (276).

La escritura de la historia de esta santa emperatriz no solamente se pone aquí en el mismo nivel que la escritura sagrada, que avala el contexto y las temáticas planteadas, sino que también se incorporan los escritos de los sabios como parte de la justificación necesaria de aquello que se postula o describe, como hace el narrador al dar cuenta de la bondad singular de la mujer expresada justamente a partir de su palabra como manifestación de verdad: "Desý era de tan buena palabra que a todas se dexava amar, ca dize el sabidor en su escripto: 'Quien bien fabla es sabidor e fazse amar a las gentes'. E Salamón diz en sus proverbios que

\footnotetext{
${ }^{26}$ La estrecha relación de estas historias piadosas con la hagiografía es abordada especialmente por César Domínguez, “'De aquel pecado que le acusaban a falsedat'. Reinas injustamente acusadas en los libros de caballerías (Ysonberta, Florençia, la santa Emperatrís y Sevilla)", Literatura de Caballerías y Orígenes de la Novela, Rafael Beltrán, ed., Universitat de València, Valencia, 1998, pp. 159-180; e Isabel Lozano-Renieblas, "El encuentro entre aventura y hagiografía en la literatura medieval", Actas del XIII Congreso de la Asociación Internacional de Hispanistas (Madrid, 6-11 de julio de 1998), Castalia, Madrid, 1998, tomo I, pp. 161-167.
} 
la boca mentiral a sý e a otro faz mal, mas aquella en que non á cosa de amargura se faz amar e onrar" (293).

Como sucedía en la historia anterior, las menciones a las Sagradas Escrituras se incrementan a medida que aumentan las pruebas que debe enfrentar la emperatriz, ya que se relacionan más directamente con el motivo literario fundamental de la acusación y persecución injustas de este tipo de heroínas tan cercanas a la santidad en su virtud ilimitada ${ }^{27}$. Estando la emperatriz en una roca en medio del mar, a merced de la muerte entre otros tantos peligros, su sufrimiento se equipara directamente con la Pasión de Jesús como horizonte de todo cristiano: "Dios mesmo llevó mucha persecuçión en su cuerpo, e diz la Escriptura que aquellos que Dios más ama, que a esos fiere más que a los que non ama" (308). La virtud probada también se referencia en la palabra santa, que ordena, resume y termina de disponer el sentido de esta historia y de cada una de las otras historias del códice como modelo de vida cristiana: "La Escriptura diz que tres cosas son que cada uno de nós se ha de conbatir, e lo que ellos pueden derribar sabet que es perdido, e estas tres sabet que coitavan mucho a la enperatrís: el mundo e la carne e el diablo; mas ella era tan firme e tan fuerte e tanto se conbatía sesudamente, que todos tres los vençía" (320).

A pesar de la unidad modélica de los protagonistas de cada uno de los relatos que integran el códice h-I-13 mediante los valores cristianos que los definen como figuras muy próximas entre sí y cercanas al ideal de la imitatio Christi, la variedad de las posibilidades de cómo concretar un camino de vida virtuosa se testimonia a partir de las temáticas singulares planteadas en cada una de las historias. En el caso de la santa emperatriz, el lazo matrimonial que se ha establecido teóricamente como equiparable a la relación de Jesús con la Iglesia se ha roto concretamente en el caso de la esposa y su marido a causa de la traición y ya no puede recuperarse, por lo que la mujer decide recluirse en un convento en lugar de regresar con quien la había condenado a muerte sin escuchar siquiera su descargo frente a las acusaciones que la difamaban, lo que es destacado por el narrador a partir de la imagen de la escritura de la otra alianza sí irrompible entre el hombre y su Sal-

\footnotetext{
${ }^{27}$ En el caso particular de esta historia, sus relaciones con la hagiografía son destacadas por Leonardo Romero Tobar, "Fermoso cuento de una enperatriz que ovo en Roma: entre hagiografía y relato caballeresco", Formas breves del relato, Aurora Egido y Yves-René Forquerne, eds., Casa de Velázquez-Universidad de Zaragoza, Zaragoza, 1986, pp. 7-18.
} 
vador: "E metiose enparedada do nunca más viese a ninguno sinón Aquel que es verdadero e poderoso sobre todo el mundo, nuestro Señor Jhesu Christo, que ella tenía escripto en su corasçón e en que folgava" (331).

La identificación final de Dios con la escritura y de la lectura como reaseguro del lazo imperecedero entre Jesús y la humanidad termina de configurar el papel del libro como registro de la relación perdurable entre el hombre y Dios y del mismo códice como un testimonio doble: de la escritura y lectura como prácticas capaces de transmitir verdades religiosas y de la compilación de historias singulares pero claramente relacionadas como expresión de un orden divino asimilable en este caso al procedimiento de la dispositio manuscrita:

E por ser a Dios bien junta se partiera de todo el mundo; nin quería otra conpaña sinón de su libro, ca bien le semejava quando por él leía que fablava con Dios e que se aconsejava con Él; onde sant Gregorio dize: "Quien quisier sienpre estar con Dios, a menudo deve leer e orar". E otrossý diz la letra: "Quien ora, quien obra, quien reza, con Dios fabla e Dios con él”. E así fazía ella. E porende non deve ninguno destorvar nin detener clérigo nin monge nin monjas de sus oraçiones, nin de leer a menudo por sus libros e de oír sus oras, ca por estas tres cosas puede omne vençer este sieglo escarnido e el enemigo, e fazer de Dios señor e amigo. E por estas tres cosas se parten ligeramente los vanos pensamientos. E por estas tres cosas fue tan guardado el santo cuerpo de la enperatrís que olvidó todo el mundo por pensar en la gloria espiritual, e allý dio su alma a Dios. (331-332)

Aunque Carlos Maynes, el último de los relatos del Ms. Esc. h-I-13, no presenta referencias explícitas a las prácticas de la escritura y la lectura medieval, su asociación temática con las dos historias precedentes la une a la misma idea transmitida en el final de Una santa enperatrís, más allá de la evidente secularización de las conductas y características de su protagonista femenina - la emperatriz Sevilla, esposa de Carlomagno - frente a la difamación inicial que la obliga a exiliarse estando embarazada y a enfrentar la aventura como prueba de su castidad, y particularmente de sus singulares ayudantes heroicos: su propio hijo, un villano y un ladrón-mago, quienes acercan aún más al posible receptor del códice en su conjunto a las muchas posibilidades y formas que asume la virtud en un contexto 
más cercano al de la transmisión de la antología manuscrita, explorando valores sustentados por la ética cristiana como la generosidad y la lealtad ${ }^{28}$.

El balance paradójico entre la variedad de los personajes y las historias del códice h-I-13 y la uniformidad de la reiteración temática y la confluencia genérica del manuscrito en su conjunto da cuenta de la compilación como una práctica regida por la imagen de la recurrencia creciente: recurrencia del motivo de la prueba cristiana en cada relato que, a través de la variación que supone en la Edad Media el concepto mismo de repetición, se vuelve una suma más significativa que cada una de sus partes.

Así como es esencial la función narrativa de la repetición en la construcción del relato - de cada relato que se configura a partir de tradiciones y modelos previos-, a nivel de la compilación de esta antología unitaria la recurrencia de las prácticas de lectura y escritura medieval funciona también de manera constructiva conforme al juego medieval incesante entre la reiteración y la variación. Como plantea al respecto Nichols, "If we accept the multiple forms in which our artifacts have been transmitted, we may recognize that medieval culture did not simply live with diversity, it cultivated it" ${ }^{29}$.

${ }^{28} \mathrm{El}$ eje lealtad-traición es fundamental en la configuración de esta última historia del Ms. Esc. h-I-13, situándose del lado de los traidores a una nobleza corrupta a la que se contraponen villanos, ladrones e incluso animales como representación de la lealtad que triunfa pese a cualquier condicionamiento social e incluso humano, como estudia John K. Maier, "Of Accused Queens and Wild Men: Folkloric Elements in Carlos Maynes”, La Corónica, 12 (1983), pp. 21-31.

${ }^{29}$ Stephen G. Nichols, "Introduction: Philology in a Manuscript Culture", Speculum, 65 (1990), pp. 1-10 (pp. 8-9). 